\title{
HUBUNGAN KEBIASAAN MEROKOK DAN STRES DENGAN HIPERTENSI PADA LANSIA
}

\author{
Musni \\ Akademi Keperawatan Batari Toja \\ Alamat Korespondensi : (musni@bataritoja.ac.id/085242544248)
}

\begin{abstract}
ABSTRAK
Hipertensi merupakan salah satu faktor penting pemicu Penyakit Tidak Menular (Non Communicable Disease $=$ NCD) yang menjadi salah satu penyebab utama kesakitan dan kematian di Indonesia. Penelitian ini bertujuan untuk mengetahui hubungan kebiasaan merokok dan stres dengan hipertensi pada lansia di Desa Welado. Metode penelitian ini menggunakan metode survey analitic dengan pendekatan cross sectional study. Teknik pengambilan sampel secara purvosive sampling dengan jumlah sampel sebanyak 50 lansia. Pengumpulan data dilakukan dengan pengukuran tekanan darah menggunakan tensimeter dan wawancara menggunakan kuesioner. Analisis data menggunakan uji statistik Chi Square dengan $\alpha=0,05$. Hasil: tidak ada hubungan ( $p$ value $=0,390$ ) antara merokok dengan hipertensi, ada hubungan antara stres ( $p$ value $=0,005$ ) dengan hipertensi pada lansia. Penanganan stres yang tepat dapat mencegah terjadinya hipertensi pada lansia.
\end{abstract}

Kata Kunci: Hipertensi, Lansia, Merokok, Stres

\section{PENDAHULUAN}

Hipertensi atau sering disebut tekanan darah tinggi adalah peningkatan tekanan darah sistolik lebih dari $140 \mathrm{mmHg}$ dan tekanan darah diastolik lebih dari $90 \mathrm{mmHg}$ pada dua kali pengukuran dengan selang waktu 5 menit dalam keadaan cukup istirahat/tenang. Hipertensi merupakan salah satu faktor penting pemicu Penyakit Tidak Menular (Non Communicable Disease $=$ NCD) seperti Penyakit Jantung, Stroke dan lainlain yang saat ini menjadi salah satu penyebab utama kesakitan dan kematian di Indonesia. (Infodatin, 2014).

Epidemi penyakit kardiovaskular terutama disebabkan oleh hipertensi. Kondisi sosial demografis, sosial ekonomi, pola makan dan pekerjaan mempengaruhi kebiasaan hidup masyarakat. Perubahan tersebut menyebabkan meningkatnya faktor risiko hipertensi seperti stres mental dan stres psikososial, merokok, aktivitas fisik, obesitas dan pola makan yang tidak sehat. Hipertensi meningkat secara tajam di banyak negara berkembang dalam dua dekade terakhir. Kehidupan modern penuh dengan kesibukan, frustrasi dan tuntutan. Stres mental atau psikososial merupakan salah satu faktor risiko utama hipertensi. Hipertensi merupakan faktor risiko untuk berbagai penyakit kardiovaskular lainnya (Jadhav, dkk, 2014).

Hipertensi juga disebut sebagai "the silent killer" karena beberapa responden tidak sadar bahwa dirinya ternyata mengalami hipertensi. Hipertensi yang berlangsung dalam jangka waktu lama dan tidak mendapat perawatan yang dibutuhkan dapat menimbulkan kerusakan pada ginjal (gagal ginjal), jantung (penyakit jantung koroner) dan otak (menyebabkan stroke) (infodatin, 2014).

Deteksi dini dan pengobatan hipertensi merupakan dasar untuk pencegahan penyakit kardiovaskular, yang merupakan penyebab utama kematian dan rawat inap di seluruh dunia. Hipertensi penyebab utama stroke, penyakit jantung koroner, gagal jantung, dan kecacatan terkait. Saat ini, seperempat hingga sepertiga dari populasi responden dewasa di AS dan di negara-negara Eropa menderita hipertensi. Tekanan darah meningkat karena usia dan sebagai akibat dari penuaan. Prevalensi hipertensi diperkirakan akan meningkat dalam beberapa dekade mendatang dan semakin banyak lansia yang harus ditangani dengan hipertensi. Ini merupakan tantangan kesehatan masyarakat yang sebenarnya untuk menyediakan layanan kesehatan, yang berdasarkan bukti-bukti ilmiah (Evidence-based). ( Daniela dkk, 2018).

Prevalensi hipertensi terus meningkat, terutama pada populasi lanjut usia, khususnya peningkatan populasi pada umur di atas 80 tahun, yang telah meluas secara eksponensial selama 40 tahun terakhir. Di Uni Eropa, ada 27,3 juta responden yang berusia 80 tahun dan pada lanjut usia (5,4\% dari total populasi) pada tahun 2016 dibandingkan pada tahun 2006 ada 20 juta $(4,6 \%$ dari total populasi. Di Amerika Serikat, persentase masyarakat umur 80 tahun dan lanjut usia diperkirakan menjadi 
$7,4 \%$ pada tahun 2050, yang dua kali lipat persentase yang diamati pada tahun 2010. Data pengamatan dari Studi Framingham menunjukkan bahwa perkembangan risiko hipertensi seumur hidup adalah> 90\% untuk individu berusia 55 - 65 tahun. Dengan demikian, peningkatan jumlah individu lanjut usia menyebabkan bertambahnya populasi dengan tekanan darah tinggi (hipertensi) (Athanase B dkk, 2019).

Hipertensi adalah faktor risiko penyakit kardiovaskular yang secara umum dapat dicegah dan merupakan masalah kesehatan di seluruh dunia, yang disebabkan faktor risiko seperti merokok dan aktivitas fisik. Hipertensi penyebab utama dalam perkembangan penyakit serebrovaskular, penyakit jantung iskemik, dan gagal ginjal. Perawatan yang tepat pada hipertensi sangat penting untuk mengurangi beban penyakit. Penyakit serebrovaskular, penyakit jantung iskemik, gagal ginjal, dan penyakit lainnya tidak hanya berhubungan dengan hipertensi saja tetapi juga dengan tekanan darah rendah. (Jena dan Purohit, 2017).

Merokok dapat menyebabkan risiko terjadinya hipertensi dan serangan jantung dan penyakit kronik. Merokok dapat menyebabkan hipertensi dan serangan jantung yang tidak hanya menyebabkan menurunnya harapan hidup tapi juga berpengaruh terhadap kualitas hidup. Tembakau pada rokok merupakan salah satu penyebab hipertensi dan serangan jantung. (Kaiye G dkk, 2017).

Dari Data World Health Organization (WHO) tahun 2015 menunjukkan sekitar 1,13 Miliar responden di dunia menderita hipertensi. artinya 1 dari 3 responden di dunia terdiagnosis menderita hipertensi, hanya 36,8 $\%$ diantaranya yang minum obat. Jumlah penderita hipertensi terus meningkat setiap tahunnya. diperkirakan pada tahun 2025 akan ada 15 Miliar responden yang terkena hipertensi. Diperkirakan setiap tahun 9,4 juta responden meninggal akibat hipertensi dan komplikasinya. (Arsyad, 2018).

Menurut Hasil Riset Kesehatan Dasar Tahun 2018, Hipertensi merupakan penyakit tidak menular yang selalu meningkat trend nya. Penderita Hipertensi beragam usianya mulai dari umur 15 tahun (remaja) hingga diatas 75 tahun (lansia). Dari 25,8 \% yang mengalami hipertensi, 2/3 diantaranya tidak mengetahui bahwa dirinya terdiagnosis hipertensi dan hanya $0,7 \%$ nya saja yang mendapatkan pengobatan hipertensi secara teratur.

Prevalensi hipertensi di Indonesia mengalami peningkatan lebih dari $8,3 \%$ yaitu dari $25,8 \%$ pada tahun 2013 menjadi $34,1 \%$ pada tahun 2018. Prevalensi hipertensi meningkat seiring dengan bertambahnya usia yaitu pada kelompok umur 45-54 tahun yaitu $45,3 \%$, umur $55-64$ tahun $55,2 \%, 65-74$ tahun $63,2 \%$ dan umur $75+$ tahun $69,5 \%$. Di Provinsi Sulawesi Selatan tahun 2016 jumlah yang menderita hipertensi yaitu 163330 responden (21.9 \%). Di Kab. Bone jumlah penderita hipertensi sebanyak 790 responden (Dinkes, 2017).

\section{BAHAN DAN METODE}

\section{Lokasi, Populasi, dan Sampel}

Jenis penelitian ini adalah analitik dengan pendekatan Cross-Sectional Study, yang dilaksanakan di Desa Welado Kec. Ajangale. Populasi pada penelitian ini adalah Seluruh Lansia yang ada di wilayah desa Welado. Sampel dalam penelitian ini adalah bagian dari populasi dan telah memenuhi kriteria inklusi dan eksklusi dengan teknik pengambilan sampel yaitu purposive sampling. Jumlah sampel sebanyak 50 lansia.

\section{Pengumpulan Data}

1. Data Primer

Pengambilan data dilakukan dengan wawancara langsung pada responden menggunakan kuesioner. Kuesioner berisi tentang karakteristik responden, kebiasaan merokok dan tingkat stress (keadaan ketegangan).

2. Data Sekunder

Data sekunder adalah Data yang diperoleh dari di Desa Welado Kec. Ajangale.

\section{Pengolahan Data}

1. Editing

Adalah upaya untuk memriksa kembali kebenaran data yang diperoleh atau dikumpulkan.

2. Coding

Merupakan kegiatan pemberian kode numerik (angka) terhaddap data yang terdiri atas beberapa kategori. Pemberian kode ini sangat penting bila pengolahan dan analisis data menggunakan komputer. Biasanya dalam pemberian kode dibuat juga daftar kode dan artinya dalam satu buku (code book) untuk memudahkan kembali melihat lokasi danarti suatu kode dari suatu variabel.

\section{Entri data}

Data entri adalah kegiatan memasukkan data yang telah dikumpulkan ke dalam master atau database komputer, kemudian membuat distribusi frekuensi sederhana atau bisa juga dengan membuat tabel kontigensi (Hidayat, 2011) 
Analisa Data

1. Analisa Univariat

Analisa untuk mengetahui presentasi dari masing-masing variabel yang akan diteliti.

2. Analisa Bivariat

Analisis data menggunakan komputer dengan menggunakan uji Chi-Square dengan tingkat kepercayan 95\% $(p<0,05)$ untuk melihat hubungan antara dua variabel yaitu variabel dependen dengan variabel independen.

\section{HASIL PENELITIAN}

1. Analisis Univariat

Tabel 1. Karakteristik responden di Desa Welado Kec. Ajangale. $(n=50)$

\begin{tabular}{|c|c|c|}
\hline Karakteristik & $\mathrm{n}$ & $\%$ \\
\hline Umur & & \\
$<65$ & 4 & 8 \\
$65-74$ & 29 & 58 \\
$>74$ & 17 & 34 \\
\hline Jenis Kelamin & & \\
Laki-laki & 22 & 44 \\
Perempuan & 28 & 56 \\
\hline
\end{tabular}

Berdasarkan tabel 1. Karakteristik responden berdasarkan umur diperoleh usia terbanyak umur 65-74 tahun yaitu sebanyak $58 \%$ dan berdasarkan jenis kelamin terbanyak pada responden perempuan yaitu $56 \%$. Responden yang mengalami hipertensi lebih banyak pada kelompok umur > 74 tahun karena semakin bertambah umur semakin rentan mengalami hipertensi.

2. Analisis Bivariat

Tabel 2. Hubungan kebiasaan merokok, dengan hipertensi pada lansia.

\begin{tabular}{|c|c|c|c|c|c|c|}
\hline \multirow{3}{*}{ Merokok } & \multicolumn{4}{|c|}{ Hipertensi } & \multirow{2}{*}{\multicolumn{2}{|c|}{ total }} \\
\hline & \multicolumn{2}{|c|}{ ya } & \multicolumn{2}{|c|}{ tidak } & & \\
\hline & $n$ & $\%$ & $\mathrm{n}$ & $\%$ & $\mathrm{n}$ & $\%$ \\
\hline Ya & 9 & 18 & 9 & $\begin{array}{l}1 \\
8\end{array}$ & $\begin{array}{l}1 \\
8\end{array}$ & 36 \\
\hline Tidak & $\begin{array}{l}2 \\
0\end{array}$ & 40 & $\begin{array}{l}1 \\
2 \\
\end{array}$ & $\begin{array}{l}2 \\
4 \\
\end{array}$ & $\begin{array}{l}3 \\
2\end{array}$ & 64 \\
\hline Total & $\begin{array}{l}2 \\
9 \\
\end{array}$ & 58 & $\begin{array}{l}1 \\
2 \\
\end{array}$ & $\begin{array}{l}4 \\
2 \\
\end{array}$ & $\begin{array}{l}5 \\
0 \\
\end{array}$ & 100 \\
\hline & & $=0$ & & & & \\
\hline
\end{tabular}

Pada tabel 2. Menunjukkan responden lansia lebih banyak yang tidak merokok dan menderita hipertensi yaitu sebanyak 40\%. Responden lansia yang merokok sama antara yang menderita hipertensi dengan yang tidak menderita hipertensi yaitu 9 responden $(18 \%)$. Dari hasil analisis chi-square nilai $\mathrm{p}=0,390$ yang berarti tidak ada hubungan antara merokok dengan hipertensi pada lansia

Tabel 3. Hubungan stres dengan hipertensi pada lansia

\begin{tabular}{|c|c|c|c|c|c|c|}
\hline \multirow{2}{*}{$\begin{array}{c}\text { Tingkat } \\
\text { Stress }\end{array}$} & \multicolumn{2}{|c|}{ Ya } & \multicolumn{2}{c|}{ Tidak } & \multicolumn{2}{c|}{ Total } \\
\cline { 2 - 7 } Sering & 5 & 10 & 0 & 0 & 5 & 10 \\
\hline Jarang & 24 & 48 & 16 & 32 & 40 & 80 \\
\hline $\begin{array}{c}\text { Tidak } \\
\text { pernah }\end{array}$ & 0 & 0 & 5 & 10 & 5 & 10 \\
\hline Total & 29 & 58 & 21 & 42 & 50 & 100 \\
\hline \multicolumn{7}{c|}{$\mathrm{P}=0,005$} \\
\hline
\end{tabular}

Berdasarkan tabel 3. Responden lansia yang paling banyak adalah yang jarang stress dan menderita hipertensi. Hasil analisi chi-square nilai $p=0,005$ berarti signifikan atau ada hubungan antara tingkat stres dengan hipertensi pada lansia.

\section{PEMBAHASAN}

1. Karakteristik Responden

Berdasarkan

karakteristik responden, umur responden lansia yang banyak mengalami hipertensi lebih banyak pada kelompok umur > 65 tahun. Faktor usia sangat berpengaruh terhadap hipertensi karena dengan bertambahnya umur maka semakin tinggi mendapat risiko hipertensi ini disebabkan oleh perubahan alamiah di dalam tubuh yang mempengaruhi jantung, pembuluh darah dan hormone. Hipertensi karena bertambahnya umur juga disebabkan karena menurunya elastisitas arteri pada proses menua, apabila tidak ditangani bisa menyebabkan gangguan jantung, ginjal dan pembuluh darah. (Vina Dwi dan Fitrah, 2010).

Perempuan pada lansia lebih banyak yang mengalami hipertensi dibanding laki-laki karena faktor hormonal. Pada umumnya perempuan lansia telah mengalami menopause, saat menopause kadar hormone estrogen pada wanita akan menurun, hormone ini yang berfungsi untuk melindungi wanita dari penyakit, efek perlindungan estrogen adalah sebagai imunitas pada usia premenopause. (Pradono, 2010)

2. Pengaruh Merokok dengan Hipertensi pada Lansia

Merokok adalah kebiasaan / perilaku menghisap rokok dan pernah 
merokok dalam kehidupan responden. Merokok sangat besar peranannya meningkatkan tekanan darah, hal ini disebabkan oleh nikotin dan karbon monoksida yang dihisap melalui rokok yang masuk kedalam aliran darah dapat merusak lapisan endotel pembuluh darah arteri dan mengakibatkan proses aterosklerosis dan tekanan darah tinggi. Nikotin yang terdapat didalam rokok juga memicu hormon adrenalin yang menyebabkan tekanan darah meningkat, selain itu nikotin juga diserap oleh pembuluh-pembuluh darah didalam paru dan diedarkan ke seluruh aliran darah lainnya sehingga terjadi penyempitan pembuluh darah. Hal ini menyebabkan kerja jantung semakin meningkat untuk memompa darah ke seluruh tubuh melalui pembuluh darah yang sempit.

Rokok mengandung lebih dari 4.000 zat beracun, ada dua zat yang sangat berperan yaitu nikotin dan karbon monoksida yang memberikan efek toksik pada jantung dan pembuluh darah. Kedua senyawa ini bersifat berbahaya dengan mekanisme yang berbeda. Nikotin merusak sistem kardiovaskular secara akut oleh stereoisomer dan mekanisme pengikatan reseptor. Nikotin berdampak pada kardiovaskular dan simpatoadrenal yang kuat. Selain itu, pemberian nikotin berulang berhubungan denga meningkatnya toleransi sebagai hasil dari reseptor nikotin. Dengan proses ini, nikotin menyebabkan tingkat kecanduan dan stimulasi sistem saraf simpatis yang berbeda. peningkatan pelepasan katekolamin dan perubahan reologi darah dengan peningkatan viskositas. ( Leone, 2015).

Hasil uji statistic menyimpulkan bahwa tidak ada pengaruh yang signifikan antara kebiasaan merokok dengan kejadian hipertensi. Pada penelitian ini responden yang tidak merokok lebih banyak dibandingkan dengan responden yang merokok. Hal ini disebabkan karena sebagian besar responden adalah perempuan. Hasil penelitian ini tidak sejalan dengan penelitian Kaiye Gao dkk tahun 2017 yaitu ada hubungan antara merokok dengan hipertensi pada responden umur 56-80 tahun di China

3. Hubungan Stres dengan Hipertensi pada Lansia
Stress sangat erat hubungannya dengan hipertensi. Stress merupakan masalah yang memicu terjadinya hipertensi di mana hubungan antara stress dengan hipertensi diduga melalui aktivitas saraf simpatis, peningkatan saraf dapat menaikkan tekanan darah intermitten (tidak menentu). Stres berkepanjangan dapat mengakibatkan tekanan darah menetap tinggi. Walaupun hal ini belum terbukti akan tetapi angka kejadian di masyarakt perkotaan lebih tinggi dibandingkan dengan pedesaan. Hal ini dapat dihubungkan dengan pengaruh stres yang dialami kelompo masyarakat yang tinggal dikota. (Suhadak, 2010).

Realita kehidupan setiap hari yang tidak bisa dihindari, stress atau ketegangan emosional dapat mempengaruhi sistem kardiovaskuler, khsusunya hipertensi, stress dianggap sebagai faktor psikologis yang dapat meningkatkan tekanan darah (wahyuningsi, 2013). Stress adalah suatu prasaan yang dialami apabila seseresponden menerima tekanan.(Syahabudding, 2010)Stres sebagai kondisi individu yang dipengaruhi oleh lingkungan. ( Evanjeli, 2012).

Hasil uji statistic menunjukkan ada hubungan antara tingkat stress dengan merokok. Hasil penelitian ini sejalan dengan penelitian (Jadhav, 2014) di India dimana tingkat stres sangat berpengaruh dengan tekanan darah sistole dan diastole. Semakin tinggi tingkat stress semakin tinggi kejadian hipertensi.

\section{KESIMPULAN}

Tidak ada pengaruh antara kebiasaan merokok dengan kejadian hipertensi pada lansia, ada pengaruh antara tinkat stress dengan kejadian hipertensi pada lansia. Untuk penelitian selanjutnya sebaiknya kebiasaan merokok lebih spesifik lagi yaitu banyak perbatang merokok dalam satu hari dan lamanya merokok, agar bisa diketahui pengaruh rokok lebih spesifik.

\section{SARAN}

1. Bagi keluarga, kiranya berperan dalam mencegah stress pada lansia dengan lebih banyak bersyukur dan mendekatkan diri pada Tuhan.

2. Bagi Peneliti Selanjutnya, untuk mengetahui hubungan rokok dengan hipertensi pada lansia sebaiknya focus sampelnya pada laki-laki, agar hasil penelitian lebih akurat. 


\section{DAFTAR PUSTAKA}

Athanase, B., Mirco, P., Timo, S. 2019. Hypertension management in older and frail older patients. Circulation Research. 124 (7), 1045-1060.

Arsyad. 2018. Ternyata hipertensi penyebab kematian No.5 di Indonesia, pare-pare.

Daniela, K., Brigitte, S. E., Valerie, S., Cinzia, D. G., Christina, W., Sven, S., ..., Arnaud, C. 2018. Screening and treatment of hypertension in older adults. Public Health Reviews. 39 (26), 3 - 16.

Infodatin. 2014. Hipertensi. Pusat Data dan Informasi Kementrian Kesehatan RI. Jakarta

Jadhav, S. B., Jatti, G. M., Jadhav, A. S., Rajderkar, S. S., Naik, J. D., Nandimath V. A. 2014. Stressing "mental stress' in hypertension a rural background study. Jurnal of Clinical and Diagnostik Reseacrh. 8 (6). 4-7

Kaiye, G., Xin, S., Wenbin, W. 2017. The life-course impact of smoking on hypertension, myocardial infarction and respiratory disease. Nature Publishing Group. 7: 4330

Kemenkes RI. 2018. Riskesdas 2018. Kementrian Kesehatan Badan Penelitian dan Pengembangan Kesehatan

Leone, A. 2015. Smoking and hypertension. Journal of Cardiology and Current Research. 2 (2). 1 - 7.

Pradono J 2010, Faktor-faktor yang mempengaruhi terjadinya hipertensi di daerah perkotaan, Gizi Indo 2010.

Jena, S. K., dan Purohit, K. C. 2017. Smoking status and its effect on blood pressure: a study on medical students. Chrismed Journal of Health and Research. 4 (1), 14-18.

Vina Dwi dan Fitrah. 2010. Memahami kesehatan pada lansia. Jakarta Trans Info Media

Wahyuningsih R. 2013 Penatalaksanaan diet pada pasien. Graha IImu. 